\title{
Pengaruh Multiple Intelligences Pada Mata Pelajaran Pai Materi Fiqih Terhadap Hasil Belajar Siswa Kelas VIII SMPN Sumber Rejo Kabupaten Musi Rawas
}

\author{
Nuraini, Joni Helandri, Yesi Arikarani
}

STAI Bumi Silampari Lubuklinggau

nura12195@gmail.com yesi.arikarani@staibsllg.ac.id jonihelandri@staibsllg.ac.id

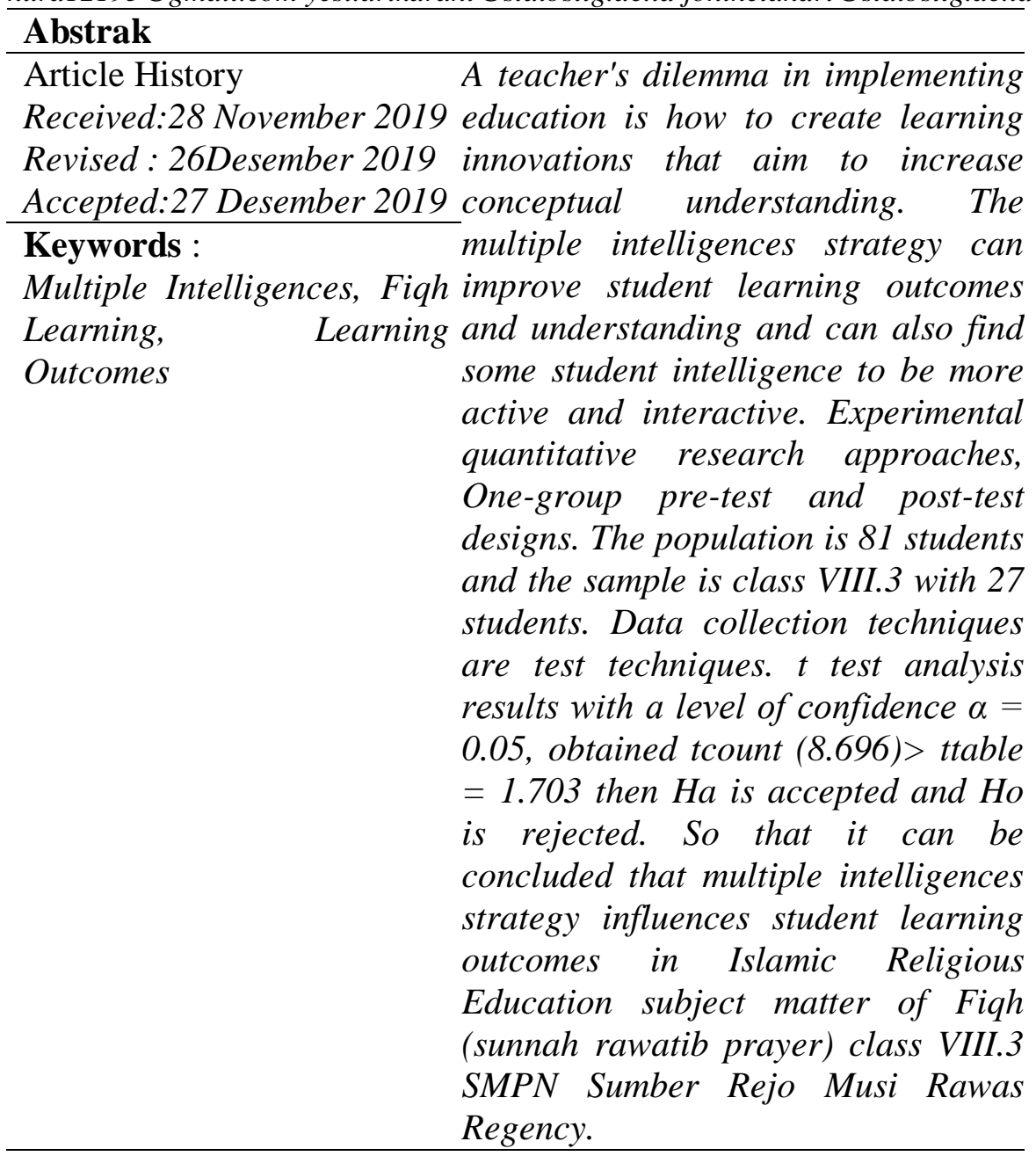

\section{Pendahuluan}

Pendidikan merupakan sarana untuk mencerdaskan peserta didik secara komperhesif, baik kecerdasan akal cerdasan akal, spiritual, maupun kecerdasan lainnya. hal tersebut searah dengan (UU No 20 tahun 2003: 3) tentang pendidikan nasional, yang menegaskan 
bahwa Pendidikan adalah usaha sadar dan terencana untuk mewujudkan suasana belajar dan proses pembelajaran agar peserta didik secara aktif mengembangkan potensi dirinya untuk memiliki kekuatan spritual keagamaan, pengendalian diri, kepribadian, kecerdasan, akhlak mulia, serta keterampilan yang diperlukan dirinya, masyarakat, bangsa dan negara.

Untuk memahami potensi setiap siswa hal yang paling utama adalah membangun kegiatan pembelajaran yang bertujuan dengan segala aktivitas guru dan siswa. Sehingga dengan demikian jika tujuan pembelajaran telah dirancang dan dirumuskan dengan baik maka sebuah program pembelajaran dalam terlaksana. Maka dari itu, pembelajaran pada dasarnya adalah proses penambahan infromasi dan kemampuan baru. Jika kita berfikir informasi dan kemampuan apa yang harus dimiliki oleh siswa, maka pada saat itu juga kita semestinya berfikit strategi apa yang harus dilakukan agar semua itu dapat dengan mudah diterima. Dalam hal ini sependapat (Yulvinamaesari 2014:100)mengenai potensi otak yakni Triune Theory merupakan sebuah temuan penting yang harus direspons secara positif oleh dunia pendidikan, terutama dalam kaitannya untuk mengembangkan sebuah strategi pembelajaran yang berbasis otak dan memberdayakan seluruh potensi diri siswa. Sering terjadi pembelajaran tradisional yang relatif hanya memfungsikan otak kecil semata, dimana proses pembelajaran yang terjadi bersifat teacher centered dengan menjadikan siswa sebagai objek pembelajaran dengan aktivitas utamanya untuk menghafal materi pelajaran, mengerjakan tugas dari guru, menerima hukuman jika melakukan kesalahan, dan kurang mendapatkan penghargaan terhadap hasil kerjanya. Syafa'at dalam (Yulvinamaesari 2014:100)

Berbicara mengenai startegi di atas merupakan hal yang sangat penting untuk dipahami, karena apa yang harus dicapai akan menentukan bagaimana cara mencapainya, oleh karena itu, peran guru sebagai pengajar, pendidik sebelum menentukan strategi pembelajaran yang digunakan maka harus memperhatikan pertimbangan apa tujuan yang ingin dicapai dalam pembelajaran, pertimbangan bahan atau materi, pertimbangan dari sudut siswa hingga ke pertimbangan lainnya yang berhubungan pada unsure terpending dalam prose belajar mengajar. Salah satu strategi pembelajaran yang di rancang sebelum melaksanakan pembelajaran adalah strategi multiple intelligence. Strategi ini berguna untuk 
mengelola kecerdasaan siswa dalam menerima informasi yang di dapat diterima serta kemampuan yang dimiliki oleh siswa.

Multiple Intelligence dalam bahasa indonesia diterjemahkan sebagai kecerdasan majemuk atau kecerdasan ganda. Tokoh pencetus teori kecerdasan ganda adalah Howard Gardner dari Harvard University, Amerika Serikat. Howard Gardner adalah seorang psikologi beraliran humanistic (kemanusiaan) guru besar pendidikan pada Graduate School Of Education. Tahun 1983 ia menulis buku berjudul Frames Of Mind: The Theory Of Multiple Intelligences. Multiple intelligence menurut Thomas Amstrong adalah "teori fungsi kognitif, dan menyatakan bahwa setia orang memiliki kemampuan dan kapasitas dalam delapan jenis kecerdasan, yaitu linguistik, spasial, kinestik-tubuh, logis-matematis, interpersonal, intrapersonal, naturalis, dan musikal". (Thomas Amstrong, 2013:15)

Dalam teori Multiple Intelligences menyarankan kepada kita untuk mempromosikan kemampuan atau kelebihan dan mengubur kelemahan kita. Proses menemukan inilah yang menjadi sumber kecerdasan seorang anak. Dalam menemukan kecerdasan, seorang anak harus dibantu oleh lingkungan, orang tua, guru, sekolah, maupun sistem pendidikan yang diimplementasikan di suatu negara. Dengan demikian strategi multiple intelligences penting bagi guru mengetahui gaya belajar masing-masing siswanya sehingga guru mampu menciptakan model pembelajaran yang menyenangkan yang berlandaskan pada gaya belajar dan kecerdasan yang ada pada masing-masing siswa. Jika siswa merasa senang dan menikmati proses pembelajaran yang berlangsung, maka dengan sendirinya minat belajar akan timbul di diri masing-masing siswa dan juga dapat meningkatkan hasil belajar siswa.

Permaslahan yang sering terjadi adalah keterlibatan guru dan siswa yang masih cenegrung pasif, siswa cenderung diam, hanya menunggu pada sajian dari guru, sehingga guru sulit dalam melihat potensi yang menonjol dalam diri siswa tersebut, pada hakikatnya kecerdasan setiap anak itu berbeda-beda ada. Secara umum kecerdasan yang dimiliki siswa terbagi menjadi tiga modalitas belajar apakah cenderung visual, auditorial atau kinestetik. Ketiga ini merupakan unsur-unsur merealisasikan belajar yang menghilangkan pasif atau cenderung dan dapat beralih dengan menyennagkan. Berdasarkan yang pernah ditulis oleh peneliti lain (Arikarani, 2019:132). Solusi dalam mengatasi permasalahn dalam mengajar 
adalah dengan menerapkan serta menciptakan pembelajaran yang menyenangkan. Dengan diawali konsep perencanaan, pelaksanaan dan evaluasi pada implementasi pembelajaran yang berbasis edutainment atau menyenangkan. (Arikarani 2017:76-77)

Pendidikan Agama Islam (PAI) berfungsi PAI berfungsi untuk membentuk kepribadian siswa supaya menjadi manusia yang berbudi luhur dan berahlak mulia.(Saragih and Dalimunthe, 2017:22) PAI yang diselenggarakan disekolah-sekolah di Indonesia pada umumnya memiliki masalah yang sama yakni minimnya metodologi dalam pembelajaran sehingga kurang dapat menarik lebih dalam belajar tentang agama Islam itu sendiri. Untuk itulah perlu adanya inovasi dalam pendidikan Agama Islam. Indonesia mewajibkan Pendidikan Agama Islam (PAI) sebagai salah satu bagian yang penting dalam mewujudkan peserta didik sehingga memiliki kompetensi dalam aspek kognitif, afektif dan psikomotorik (IQ dan EQ. (Saragih and Dalimunthe 2017:22) maka dengan menggunakan pembelajaran berbasis Multiple Intelligences ke dalam strategi pembelajaran dapat mencapai tujuan pembelajaran yang diinginkan serta dmewujudkan siswa menjadi kepribadian yang berakhlak mulia.

Memahami permasalah pada fokus penelitian peneliti bahwa menurut (Wawancara Ibu Apnita guru PAI VIII di SMPN Sumberrejo) beliau mengatakan bahwa "guru sebelumnya belum menggunakan strategi pembelajaran Multile Intelligences dalam proses belajar mengajar guru masih menggunakan proses pembelajaran konvensional. Sehingga jelas ingin menerapkan startegi pembelajarn multiple intelligence bertujuan untuk menguji teori dan melihat hasil penelitiannya. Pemetaan penelitian ini menguji, menghitung dan menganalisis secara alamiah tentang Pengaruh Multiple Intelligences Pada Mata Pelajaran PAI Materi Fiqih Terhadap Hasil Belajar Siswa Kelas VIII SMPN Sumber Rejo Kabupaten Musi Rawas.

\section{Metode Penelitian}

Jenis dan Desain Penelitian

Berdasarkan permasalahan yang diteliti, maka jenis penelitian ini adalah penelitian kuantitatif, Multiple Intelligences dengan penelitian rancangan One-Grop Pre-Tes And Post-Test Design. Di dalam desain ini observasi dilakukan sebanyak 2 kali yaitu sebelum eksperimen dan sesudah eksperimen. Desain penelitian yang 
digunakan berbentuk One Gruop Pre-test dan Post-test (Sugiyono,Statistik Penelitian). Dapat digambarkan seperti dibawah ini:

Tabel 3.1

Desain Penelitian

\begin{tabular}{|c|c|c|}
\hline Pre-test & Treatment & Post-test \\
\hline $\mathrm{O}_{1}$ & $\mathrm{X}$ & $\mathrm{O}_{2}$ \\
\hline
\end{tabular}

Keterangan:

$\mathrm{O}_{1}$ : Nilai Pretest (sebelum dilakukan perlakuan)

$\mathrm{X}$ : Treatment atau perlakuan menggunakan strategi berbasis Multiple intelligences

$\mathrm{O}_{2}$ : Nilai posttest (Setelah dilakukan perlakuan)

Pengaruh strategi pembelajaran PAI berbasis Multiple intelligences terhadap hasil belajar siswa adalah $\left(\mathrm{O}_{2-} \mathrm{O}_{1}\right)$.

Populasi dan sampel

Populasi merupakan wilayah generalisasi yang terdiri atas objek/ subjek yang mempunyai kualitas dan karakteristik tertentu ditetapkan oleh peneliti untuk dipelajari dan kemudian ditarik kesimpulannya”. (Sugiyono, 2014:117) Populasi dalam penelitian ini adalah seluruh siswa kelas VIII.1 yang berjumlah 81 siswa.

Tabel 3.2

Populasi Penelitian

\begin{tabular}{|c|c|c|c|c|}
\hline \multirow{2}{*}{ No } & \multirow{2}{*}{ Kelas } & \multicolumn{3}{|c|}{ Jenis Kelamin } \\
\cline { 3 - 5 } & Laki-Laki & Perempuan & Jumlah \\
\hline 1 & $\mathrm{VIII}_{1}$ & 16 & 13 & 29 \\
\hline 2 & $\mathrm{VIII}_{2}$ & 15 & 10 & 25 \\
\hline 3 & $\mathrm{VIII}_{3}$ & 14 & 13 & 27 \\
\hline \multicolumn{2}{|l}{ Jumlah } & $\mathbf{4 5}$ & $\mathbf{3 6}$ & $\mathbf{8 1}$ \\
\hline
\end{tabular}

Sumber: Tata Usaha SMP Negeri Sumber Rejo Tahun Ajaran 2019

Sampel

Sampel menurut sugiyono adalah bagian dari jumlah dan karakteristik yang dimilii oleh populasi. (Sugiyono, 2014:118) Untuk penelitian ini, teknik yang digunakan untuk mengambil sampel adalah "simple random sampling atau pengambilan sampel secara acak tanpa memperhatikan strata yang ada dalam populasi itu. (Sugiyono, 2014:120) Kelas VIII.3 di SMP Negeri Sumber Rejo dianggap lebih homogen dari kelas VIII lainnya karena nilai rata-rata siswa yang pandai dan kurang pandai tidak jauh berbeda. Jadi sampel dalam penelitian ini kelas VIII.3 berjumlah 27 siswa. 


\section{Teknik Pengumpulan Data}

a. Tes

Menurut Arikunto tes adalah "seretan pertanyaan atau latihan serta alat lain yang digunakan untuk mengukur ketrampilan, pengetahuan inteligensi, kemampuan atau bakat yang dimiliki oleh individu atau kelompok.(Suharsimi Arikunto, 2013:193) Tes yang diberikan yaitu tes objektif berbentuk multiple choice (pilihan ganda) dengan empat pilihan jawaban (obition) pada masing-masing soal. Soal tersebut berjumlah 10 soal yang sebelumnya telah dilakukan pengujian terhadap validitas dan reabilitas tes.

b. Observasi

Observasi dalam penelitian ini merupakan teknik pengumpulan data dengan cara mengamati setiap kejadian yang sedang berlangsung dan mencatatnya dengan alat observasi tentng hal-hal yang akan diamati atau diteliti(Sugiyono, 2014:86)

\section{Vadilitas Dan Relibilitas Instrumen}

1. Vadilitas Tes

Koofesien bisa dihitung dengan menggunakan rumusan korelasi Prduct moment angka kasar yaitu:

$$
r \mathrm{Xy}=\frac{\mathrm{n} \Sigma \mathrm{XY}-(\Sigma X)(\Sigma Y)}{\sqrt{\left\{n \cdot \Sigma X^{2}-(\Sigma X)^{2}\right\} \cdot\left\{n \cdot \Sigma Y^{2}-(\Sigma Y)^{2}\right\}}}
$$

Keterangan:

$r x y=$ koefisien korelasi antara Variabel X dan Variabel Y

$n$ = Banyaknya peserta tes

$X=$ Nilai hasil uji coba

$Y=$ Nilai rata-rata harian

$\sum x y=$ jumlah perkalian antara $\mathrm{X}$ dan $\mathrm{Y}$ (Sugiyono, 213)

Nilai $r_{x y}$ yang diperoleh dapat di interprestasikan untuk menentukan validasi butir soal dengan menggunakan kriteria pada Tabel klasifikasi validitas butir soal pada tabel 3.3 berikut.

Tabel 3.3

Interpretasi Validitas Butir Soal

\begin{tabular}{|c|c|}
\hline Nilai $\boldsymbol{r}_{x y}$ & Kriteria \\
\hline $0.80<r x y \leq 1.00$ & Validitas Sangat Tinggi \\
\hline
\end{tabular}




\begin{tabular}{|c|c|}
\hline $0.60<r x y \leq 0.80$ & Validitas Tinggi \\
\hline $0.40<r x y \leq 0.60$ & Validitas Cukup \\
\hline $0.20<r x y \leq 0.40$ & Validitas Rendah \\
\hline $0.00<r x y \leq 0.20$ & Validitas Sangat Rendah \\
\hline
\end{tabular}

2. Uji Reliabilitas

Menurut Arikunto Reliabilitas menunjukan pada suatu pengertian bahwa sesuatu instrumen cukup dapat dipercaya untuk digunakan sebagai alat pengumpul data karena instrumen tersebut sudah baik.(Sugiyono, 213) Untuk menghitung reliabilitas tes (uji pre-tes) bentuk uraian yang digunakan rumus sebagai berikut:

Rumus Alpha:

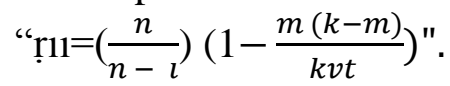

Keterangan:

r11 = Reliabilitas instrumen

$\mathrm{k}$ = Banyaknya butir pertanyaan atau banyaknya soal

$\mathrm{M}=$ Skor rata-rata

$V t \quad=$ varians total. (Sugiyono, 232)

Krikteria derajat reabilitas yaitu sebagai berikut.

Tabel 3.4. Derajat Reliabilitas

\begin{tabular}{|c|c|}
\hline Koefisien Korelasi $\left(\boldsymbol{r}_{\mathbf{1 1}}\right)$ & Kriteria \\
\hline$r_{11} \leq 0.20$ & Reliabilitas Sangat Rendah \\
\hline $0.20<r_{11} \leq 0.40$ & Reliabilitas Sedang \\
\hline $0.40<r_{11} \leq 0.60$ & Reliabilitas Tinggi \\
\hline $0.60<r_{11} \leq 0.80$ & Reliabilitas Sangat Tinggi \\
\hline $0.80<r_{11} \leq 1.00$ & \\
\hline
\end{tabular}

Setelah hasil uji coba instrumen dianalisis dengan mengunakan rumus Alpha. Diperoleh koefisien reliabilitas sebesar 0.50. ini bearti soal tes tersebet mempunyai reliabilitas sedangs dan dapat dipercayai sebagai alat ukur 3 Tingkat Kesukaran. 


\section{Tingkat Kesukaran}

Untuk menghitung tingkat kesukaran butir soal atau biasa disebut juga indeks kesukaran digunakan rumus sebagai berikut:

$$
\text { "P }=\frac{B}{J S} " \quad(\text { Sugiyono, 223) }
$$

Keterangan:

$\mathrm{P} \quad=$ Indeks kesukaran

B = banyaknya siswa yang mwnjawab soal itu dengan benar

JS = Jumllah seluruh peserta tes

Kriteria interprestasi tingkat kesukaran butir soal menurut Sudjana (1999:137) adalah sebagai berikut:

Tabel 3.5

Interprestasi Tingkat Kesukaran

\begin{tabular}{|c|c|}
\hline Tingkat Kesukaran & Krikteria \\
\hline $0,00-0,30$ & Soal Sukar \\
\hline $0.31-0,70$ & Soal Sedang \\
\hline $0,70-100$ & Soal Mudah \\
\hline
\end{tabular}

Daya Pembeda

Menghitung daya pembeda (DP) butir soal bentuk uraian, maka di gunakan rumus sebagai berikut:

$$
\mathrm{D}=\frac{B A}{J A}=\frac{B A}{J B}=P A-P B .(\text { Sugiyono, } 228)
$$

Keterangan:

$D \quad=$ indeks diskriminasi item

$J A \quad=$ banyaknya Siswa kelompok atas

$J_{B} \quad$ = banyaknya kelompok bawah

$B A=$ Banyaknya siswa kelompok atas yang menjawab soalitu dengan benar

$P A=$ Proposi siswa kelompok atas yang menjawab benar

$P B=$ Proposi siswa kelompok bawah yang menjawab benar

Kriteria Interprestasi Daya Pembeda instrumen sebagai berikut:

Tabel 3.6

Interprestasi Daya Pembeda

\begin{tabular}{|c|l|}
\hline Interprestasi Daya Pembeda & \multicolumn{1}{|c|}{ Kriteria } \\
\hline $\mathrm{DP} \leq 0,00$ & Sangat Buruk \\
\hline $0,00<\mathrm{DP} \leq 0,20$ & Buruk \\
\hline $0,20<\mathrm{DP} \leq 0,40$ & Cukup \\
\hline $0,40<\mathrm{DP} \leq 0,70$ & Baik \\
\hline
\end{tabular}




\section{Teknik Analisis Data}

\begin{tabular}{l|l}
$0,80<\mathrm{DP} \leq 1,00$ & Sangat baik
\end{tabular}

1. Uji Normalitas Data

Uji normalitas bertujuan untuk melihat apakah kedua kelompok data berdistribusi normal atau tidak. (Sugiyono, 2010: 107) Rumus yang digunakan dalam uji normalitas yaitu:

$$
\text { “ } \mathrm{K}_{\mathrm{m}}=\frac{x-M o}{S} \text { ". (Heryanto, 2012: 243) }
$$

Keterangan:

$$
\begin{array}{ll}
\mathrm{K}_{\mathrm{m}} & =\text { kemiringan kurva } \\
\mathrm{X} & =\text { Rata-rata } \\
\mathrm{S} & =\text { Simpangan baku }
\end{array}
$$

Kemudian $=x^{2}$ hitung dibandingkan dengan $x^{2}$ tabel, dengan drajat kebebasan $(\mathrm{dk})=\mathrm{n}-1$, dimana $\mathrm{n}$ adalah banyak kelas interval data dengan taraf signifikansinya 5\%. Jika $x^{2}$ hitung $<x^{2}$ tabel, maka dapat dikatakan bahwa data tersebut berdistribusi normal, dan jika $x^{2}$ hitung $\geq x^{2}$ tabel dinyatakan bahwa data tersebut tidak berdistribusi normal.

2. Uji Hipotesis

Dalam penelitian ini uji hipotesis menggunakan uji t. sebagai berikut:

$$
\text { " } \mathrm{t}=\frac{M d}{\sqrt{\frac{\sum x d 2}{n(n-1)}}} .
$$

keterangan:

Md = Mean dari deviasi antara posttest dan pretest

$\mathrm{xd}=$ Deviasi masing-masing subjek

$\sum x d 2=$ Jumlah kuadrat deviasi

$\mathrm{N} \quad=$ Subjek pada sampel varians kelompok eksperimen

Kriteria pengujian terima Ho jika $t_{\text {hitung }}<t_{\text {tabel }}$ dan tolak Ho jika $t_{\text {hitung }}>t_{\text {tabel, }}$ maka dimana $t_{\text {tabel }}$ adalah $t$ yang didapat dari tabel distribusi $\mathrm{t}$ dengan $\mathrm{dk}=\mathrm{n}-1$ dan $\mathrm{a}=5 \%$.

\section{Hasil}


Dalam penelitian ini tes telah diberikan sebanyak dua kali, yaitu tes awal (pre-tes) dan tes akhir (post-test). Tes awal (pre-tes) diberikan untuk mengetahui kemampuan awal yang dimiliki siswa sebelum diberi perlakuan. Sedangkan tes akhir (post-test) diberikan untuk mengetahui hasil belajar siswa setelah diberikan perlakuan. Bentuk tes yang telah digunakan adalah pilihan ganda sebanyak 8 soal dengan yang sama masing-masing soal. Skor tersebut kemudian dikonversikan menjadi nilai dengan cara membagikan skor mentah siswa dengan skor maksimal dikali dengan 80 . Dengan demikian nilai minimum 0 dan maksimum 80 . Dengan rumus berikut:

$$
\mathrm{NH}=\frac{J B}{J S} \mathrm{X} 100
$$

Tabel 4.5

Rekap Nilai Pretest Dan Posttest

\begin{tabular}{|c|c|c|c|}
\hline No. & Nama Siswa & Nilai Pretes & Nilai Posttest \\
\hline 1 & M-1 & 63 & 88 \\
\hline 2 & M-2 & 63 & 88 \\
\hline 3 & M-3 & 63 & 88 \\
\hline 4 & M-4 & 75 & 88 \\
\hline 5 & M-5 & 50 & 88 \\
\hline 6 & M-6 & 38 & 100 \\
\hline 7 & M-7 & 75 & 88 \\
\hline 8 & M-8 & 75 & 100 \\
\hline 9 & M-9 & 38 & 88 \\
\hline 10 & M-10 & 38 & 63 \\
\hline 11 & M-11 & 88 & 88 \\
\hline 12 & M-12 & 50 & 63 \\
\hline 13 & M-13 & 25 & 63 \\
\hline 14 & M-14 & 38 & 88 \\
\hline 15 & M-15 & 75 & 100 \\
\hline 16 & M-16 & 75 & 100 \\
\hline 17 & M-17 & 63 & 100 \\
\hline 18 & M-18 & 63 & 75 \\
\hline 19 & M-19 & 50 & 88 \\
\hline 20 & M-20 & 63 & 88 \\
\hline 21 & M-21 & 100 & 100 \\
\hline 22 & M-22 & 63 & 88 \\
\hline 23 & M-23 & 75 & 88 \\
\hline 24 & M-24 & 50 & 88 \\
\hline 25 & M-25 & 63 & 75 \\
\hline 26 & M-26 & 75 & 88 \\
\hline 27 & M-27 & 75 & 100 \\
\hline & Jumlah & 1769 & 2359 \\
\hline & & & \\
\hline
\end{tabular}


Data hasil pretest dan posttest yang terkumpul kemudian dikelompokan berdasarkan rentang data, banyak kelas dan panjang kelas interval. Selanjutnya disusun tabel distribusi frekuensi dengan langkah-langkah sebgai berikut:

\section{Data Pretest}

a. Rentang data, yaitu data terbesar dikurang data terkecil.

$\mathrm{R}=$ data terbesar-data terkecil $=100-25=75$

b. Banyak kelas interval dengan rumus $1=3,3 \log n$

$$
\begin{aligned}
\mathrm{K} & =1+3,3 \log \mathrm{n} \\
& =1+3,3 \log 27 \\
& =1+3,3 \times 1,3 \\
& =1+4,29=5,29 \text { maka panjang kelas intervalnya } 6
\end{aligned}
$$

c. Panjang interval $=\frac{\text { rentang }}{\text { banyak kelas }}$

$$
\begin{aligned}
& =\frac{75}{6} \\
& =12.5 \\
& =13 \text { panjang kelas intervalnya } 13
\end{aligned}
$$

Tabel 4.6. Tabel Distribusi Frekuensi Nilai Pretest

\begin{tabular}{|c|c|c|c|c|c|}
\hline Interval & $\mathrm{F}_{\mathrm{i}}$ & $\mathrm{X}_{\mathrm{i}}$ & $\mathrm{X}_{\mathrm{i}}^{2}$ & $\mathrm{~F}_{\mathrm{i}} \mathrm{X}_{\mathrm{i}}$ & $\mathrm{F}_{\mathrm{i}} \mathrm{X}_{\mathrm{i}}^{2}$ \\
\hline $13-27$ & 1 & 25 & 625 & 25 & 625 \\
\hline $28-45$ & 4 & 42 & 1,764 & 168 & 28224 \\
\hline $43-57$ & 4 & 50 & 2500 & 200 & 40000 \\
\hline $58-72$ & 8 & 65 & 4225 & 520 & 270400 \\
\hline $73-87$ & 8 & 80 & 6400 & 640 & 409600 \\
\hline $88-100$ & 2 & 95 & 9025 & 190 & 36100 \\
\hline Jumlah & 27 & 357 & 24539 & 1743 & 784949 \\
\hline
\end{tabular}

d. Mean Pretest $(\mathrm{X})=\frac{\sum \text { Fi Xi }}{N}=\frac{1743}{27}=64,5$

\section{Data Posttest}

a. Rentang data, yaitu data terbesar dikurang data terkecil.

$\mathrm{R}=$ data terbesar-data terkecil $=100-63=37$

b. Banyak kelas interval dengan rumus $1=3,3 \log n$ $K=1+3,3 \log n$ 
76 Nuraini, Joni dan Yesi, Pengaruh Multiple Intelligences,.....

$$
\begin{aligned}
& =1+3,3 \log 27 \\
& =1+3,3 \times 1,3 \\
& =1+4,29=5,29 \text { maka panjang kelas intervalnya } 6
\end{aligned}
$$

c. Panjang interval $=\frac{\text { rentang }}{\text { banyak kelas }}$

$$
\begin{aligned}
& =\frac{37}{6} \\
& =6.16 \\
& =7 \text { panjang kelas intervalnya } 7
\end{aligned}
$$

Tabel 4.7

Tabel Distribusi Frekuensi Nilai Pretest

\begin{tabular}{|c|c|c|c|c|c|}
\hline Interval & $\mathrm{F}_{\mathrm{i}}$ & $\mathrm{X}_{\mathrm{i}}$ & $\mathrm{X}_{\mathrm{i}}^{2}$ & $\mathrm{~F}_{\mathrm{i}} \mathrm{X}_{\mathrm{i}}$ & $\mathrm{F}_{\mathrm{i}} \mathrm{X}_{\mathrm{i}}^{2}$ \\
\hline $63-70$ & 3 & 66,5 & 4422.25 & 199.5 & 39800.25 \\
\hline $71-78$ & 2 & 74,5 & 5550.25 & 149 & 5550.25 \\
\hline $79-86$ & 0 & 82,5 & 6806.25 & 0 & 0 \\
\hline $87-94$ & 15 & 90,5 & 8190.25 & 1357.5 & 184280.625 \\
\hline $95-100$ & 7 & 98,5 & 9702.25 & 689.5 & 475410.25 \\
\hline $103-110$ & 0 & 106,5 & 11342.25 & 0 & 0 \\
\hline Jumlah & 27 & 5235 & 460135 & 23955 & 23635670 \\
\hline
\end{tabular}

d. Mean Pretest $(\mathrm{X})=\frac{\sum \mathrm{Fi} \mathrm{Xi}}{N}=\frac{23955}{27}=88.7$

\section{Analisis data penelitian}

a. Analisis Data Tes

Tabel 4.8. Analisis Nilai Pretest Dan Posttest

\begin{tabular}{|c|c|c|}
\hline Variabel & Pretest & Posttest \\
\hline $\mathrm{X}$ & 64.5 & 88.7 \\
\hline $\mathrm{S}_{\mathrm{i}}$ & 160,81 & 302,70 \\
\hline
\end{tabular}

b. Uji normalitas

Tabel 4.9. Hasil Uji Normalitas Nilai Pretest Dan Postest

\begin{tabular}{|l|l|l|}
\hline Variabel & Pretest & Postest \\
\hline $\mathrm{Km}$ & $-0,04$ & 0,03 \\
\hline
\end{tabular}

c. Pengujian Hipotesis

Tabel 4.10. Hasil uji hipotesis nilai Pre-tes dan Post-test

\begin{tabular}{|c|c|}
\hline Variabel & Nilai \\
\hline $\mathrm{t}_{\text {hitung }}$ & 8,696 \\
\hline
\end{tabular}




\section{\begin{tabular}{|c|c|}
\hline $\mathrm{t}_{\text {tabel }}$ & 1,703 \\
\hline
\end{tabular}}

Uji hipotesis menggunakan $\mathrm{dk}=\mathrm{n}-1=27-1=26$ dan $\mathrm{a}=$ 0,05. karena $t_{\text {hitung }}>t_{\text {tebel }}$ maka tolak Ho dan terim Ha, sehinggga dapat disimpulkan bahwa ada pengaruh yang signifikan anatara strategi pembelajaran berbasis multiple intelligences terhadap hasil belajar siswa pada materi fiqih di SMPN Sumber Rejo Kabupaten Musi Rawas.

\section{Pembahasan}

Dari hasil data tes awal (pre-test) bertujuan untuk mengetahui kemampuan awal siswa sebelum diberikan perlakuan dengan menggunakan strategi pembelajaran multiple intelligence pada mata pelajaran PAI materi Fiqih nilai rata-rata yaitu 64.5. Dengan nilai tertinggi yaitu 100 dan nilai terendah yaitu 25. Jumlah siswa yang mendapatakan nilai diatas rata-rata adalah sebanyak 10 siswa. Dan yang mendapat nilai dibawah rata-rata adalah sebanyak 17 siswa. Agar hasil dapat lebih terpercaya datanya, maka peneliti menguji kenormalan data tersebut. Uji normalitas diperlukan untuk dapat melanjutkan pada uji t, dalam hal ini unyuk menguji hipotesis penelitian.

Analisis yang telah dilakukan untuk uji normalitas data mengganakan rumus kemiringan karl person dan diperoleh hasil bahwa data tersebut berdistribusi normal. Dengan melakukan uji statistik atau uji $t$ sebagai penguji hipotesis maka didapat nilai $t_{\text {hitung }}$ 8,696 . Sedangkan nilai $t_{\text {tabel }}$ yang diperoleh dari tabel distribusi $t$ yaitu 1,703. Berdasarkan kriteria pengujian hipotesis, jika $t_{\text {hitung }}>t_{\text {tabel }}$ maka Ho ditolak dan Ha diterima, jika $t_{\text {hitung }}<t_{\text {tabel, }}$, maka Ho diterima dan Ha ditolak. Karena $t_{\text {hitung }}>t_{\text {tabel, }}$ maka Ho ditolak dan Ha diterima, artinya penerapan strategi pembelajran multiple intelligences berpengaruh terhadap hasil belajar siswa pada mata pelajaran PAI materi Fiqih di sekolah pada kelas VIII.3 SMPN Sumber Rejo Kabupaten Musi Rawas.

Berdasarkan pengamatan selama melakukan penelitian dengan memberikan perlakuan sebanyak 2 kali pertemuan dikelas eksperimen tersebut dengan menggunakan strategi pembelajran multiple intelligences, ternyata terlihat dalam proses pembelajaran yang sedang berlangsung didalam kelas, adanya interaksi anatara si peneliti dan siswa, dimana ketika peneliti mmemberikan materi pembelajaran tentang Fiqih dengan menggunakan strategi 
pembelajran multiple intelligences. Siswa mengekspresikan dirinya dengan menunjukan mimik wajah senang dan gembira serta mudah memahami bagaimana pembelajaran yang diberikan oleh peneliti, pada saat peneliti menggunakan pendekatan multiple intelligences siswa secara tertib menyimak dan memperhatikan dengan seksama. Kemudian terlihat bahwa penggunakan pendekatan multiple intelligences termasuk dalam kategori baik terbukti dari hasil analisis observasi sikap antusias siswa menanggapi materi. Hal tersebut dapat dilihat dari hasil belajar siswa, terlihat adanya perbedaan anatara hasil belajar siswa sebelum diberikan perlakuan (pre-test) dan setelah diberi perlakuan (post-test) yaitu dengan menunjukan nilai rata-rata hasil pre-test.

Dalam penelitian ini terdapat juga kendala-kendala dalam pelaksanaan penelitian, diantaranya adalah kurangya fasilitas sekolah yang menjadikan kendala dalam penerapan startegi pemebelajaran multiple intelligences, serta pada saat proses pembelajaran berlangsung situasi dan kondisi didalam kelas menjadi kurang terkontrol sebelum dimulainya pembelajaran, namu setelah proses pembelajaran berlangsung dan peneliti mulai menjelaskan dengan strategi pembelajaran multiple intelligences siswa mulai hening dan memperhatikan secara seksama materi pembelajran yang disampaikan oleh peneliti.

\section{Simpulan}

Berdasarkan data pre-test dan post-test terlihat bahwa nilai atarata pre-test berbeda signifikan dengan nilai rata-rata post-test. Nilai rata-rata pre-tets yaitu 64.5 dan rata-rata post-test siswa adalah 88.7 selain itu berdasarkan hasil analisis statistik terhadap data post-test yang dengan melakukan uji hipotesis diperoleh nilai $t_{\text {hitung }}=, 696$ sedangkan $t_{\text {tabel }}=1,703$ sehingga Ho ditolak dan Ha diterima. Dengan demikaian dapat disimpulkan bahwa ada pengaruh yang signifikan anatra strategi pembelelajaran multiple intelligences terhadap hasil belajar siswa kelas VIII. 3 pada mata pelajaran PAI materi Fiqih di SMPN Sumber Rejo Kabupaten Musi Rawas. 


\section{DAFTAR PUSTAKA}

Amstrong, Thomas, 2005. Setiap Anak Cerdas (Panduan Membantu Anak Belajar Dengan Memanfaatkan Multiple IntelligenceNya), Jakarta: PT. Gramedia Pustaka Utama.

Armstrong, Thomas. 2013. Kecerdasan Multipel Didalam Kelas. Jakarta: PT Indeks.

Arikarani, Yesi. 2017. "Implementasi Edutainmen Dalam Pembelajran AL-Qur'an Bagi Siswa SDIT Mutiara Cendekia Lubuklinggau." El-Ghiroh XIII, No.(September):67-69.

Arikarani, Yesi. 2019. "Analisis Edutainment Dan Brain-Based Learning Perspektif Psikologi Pembelajaran PAI Dan Agama A . Pendahuluan Dewasa Ini , Disengaja Atau Tidak, Perubahan Yang Terjadi Melalui Proses Belajar Ini Bisa Kearah Yang Jelas Lebih Baik Atau Malah Sebaliknya , K.” Edukasia 14(1):12556.

Arikunto. Suharsimi. 2012. Prosedur Penelitian (Suatu Pendekatan Praktik). Jakarta: Rineka Cipta.

Saragih, Alkausar and Marija Dalimunthe. 2017. "Strategi Gaya Pembelajaran Pendidikan Agama Islam." Amaliah: jurnal pengabdian kepada masyarakat 1(1 Mei 2017):21-24.

Sanjaya, Wina. 2008. Perencanaan Dan Desain Sistem Pembelajaran. Jakarta: Kencana.

Sugiyono, Metode Penelitian Pendidikan Pendekatan Kuantitatif, Kualitatif, Dan R\&D. Bandung: Alfabeta, 2014.

Sugiyono, Statistik Penelitian. Alfabeta: Bandung, 2014.

Suprihatiningrum, Jamil. 2016. Strategi Pembelajaran. Yogjakarta: Ar-Ruzz Media. 
80 Nuraini, Joni dan Yesi, Pengaruh Multiple Intelligences,.....

Yulvinamaesari, Universitas Cokroaminoto Palopo. 2014. "Implementasi Brain Based Learning Dalam Pembelajaran." Pp. 99-214 in Prosiding Seminar Nasional. Vols. 01, Nomor. 